\title{
Heart Chamber Enlargement Indicator
}

National Cancer Institute

\section{Source}

National Cancer Institute. Heart Chamber Enlargement Indicator. NCI Thesaurus. Code C139062.

An indication as to whether there is an enlarged heart chamber. 